\title{
Investigate the Computer Information Network Security Technology and the Development Direction
}

\author{
Teng Ping \\ Liaoning Police College, Liaoning, 116036 China
}

\begin{abstract}
After China's accession to the WTO, the computer information network security technology of our country has a rapid development, bring many conveniences for the people's life and work, indirectly changing their daily life and working mode. For the whole development situation of our country, the development direction of informatization is the inevitable trend of development in our country, while the using process of computer information network security technology in the society still exist many problems, and the network security will be threatened to some extent. Therefore, people pay a higher attention to the security problems of computer information network technology.
\end{abstract}

Keywords. Computer, information network, security technology, development direction.

\section{Introduction}

As the technology of our country has already reached a certain height, the computer network resources become an important power to rapid developing of Chinese society. The development of computer network information technology has laid a solid foundation for our country's social development. It today's computer network information technology that has deep into the society in the economic, political, military, science and technology, daily life habits and work habits and other fields, which transforms the people's daily life habits and way of life to a large extent, and realizes the socialization of computer development in the true sense. The development and change of the information age are very quick, so it often appears many problems inevitably. Consequently, we need continuously to develop, update and perfect computer network information security technology to solve these inevitable problems.

\section{The computer information network security technology}

There are many kinds of levels for computer information network security protection, which is being widely used and well-developed has the following kinds:

One is the firewall technology. Firewall technology refers to the separate by predefined strategy between intranet and extranet, is safety measures of implement mandatory access supervision on the Intranet and extranet communication. Its main contents are hiding the inside network structure, the promotion of security access and control to network, constraining the visiting etween internal network users and outside users, and preventing external users from using illegal means to attack the internal network, steal internal data and endanger the safety environment of internal network operating system. The way of checking the two or more network transmission data, link way, is carried out in accordance with certain security policies. Whether various network can communicate with each other is determined by testing results, The firewall also can effectively monitor network running status, as long as some suspicious behavior appear, will 
conduct the early warning. It will automatically provide network testing on whether there areattacksand so on.Firewall uses the way of the separation of intranet and extranet can isolate the key website in the intranet site, in order to avoid the internal information leakage, reduce local focus, network security issues impact on the risks of the global network.

The second is data encryption technology. The data encryption information of computer information network security technology is to transcode and recode the clear data, transform the previous data into a cipher text data, then transform the cipher text back into clear data when applying. This is the data encryption technology. Its main purpose is to hide the information content and protest the information security. For the dynamic information, data encryption technology is a kind of protective measure. An encryption system including many types, such as expressly set, cipher, the key data collection and algorithm. On the specific, the algorithm includes some calculation formula, rules or procedures. We can say that for the confidentiality of data, data encryption technology has been a technology with high confidentiality, which is more used in the society, improving the confidentiality of data, preventing from being stolen and modified.

Three is intrusion detection technology. In computer information network security technology, intrusion detection technology can timely discover and report the technical means involving abnormal or unauthorized phenomenon in the computer system of. Under the premise that does not affect the network performance, real-time monitoring computer information network, including internet use behavior, packets, security logs, etc., indentifing movable which does not been wanted to happen in the network, protecting the network security problems caused by network attack and misoperation, to ensure the safety of the information resources in the system. Intrusion detection is known as the second exit after the firewall, that can be divided into three kinds of measurement methods, namely: the intrusion detection based on the network, intrusion detection based on computer hostand hybrid intrusion detection. The most widely used one is the intrusion detection based on network security.

Fourth, vulnerability scanning technology. Computer information network vulnerability refers to the safety defects of the using computer hardware, software and strategies, which will make the network system of attacker invasion into the internal network, with a very short time, easily, and access, steal, control network system resources. Therefore, the vulnerability scanning system can automatically detect the hardware, software, and strategy of the local or remote host, etc. Vulnerability scanner collect information through service ports of various network query, host, local host or a remote system scan, and use the shortest possible time to query each other bugs and security hidden danger existing in the network system, and help workers timely, accurately, and systematically grasp the network security situation, make system optimization, configuration, timely repair, update, improve the network system of loopholes and safe hidden trouble, remedy the holes of network security maximum, and eliminate safety hidden trouble.

Five is the visualization technology in network security. Visualization technology of the computer information network security is a reasonable complement and perfect for the firewall technology, vulnerability scanning technology, intrusion detection technology. The visualization technology of network security is a reference to human visual model and the ability of structure framework, to show people massive high abstract data in a network with presents, graphics, images, and other forms, to be used in the network communication real-time show special information to the people. Network security visualization also is the real reflection of the entire network running status currently we use. The visualization technology take the information network security risks exist in the operation on a humane way accurately to the user. Visualization technology can help network security analysis workers with the most intuitive way to fast, accurate and comprehensive information network of the bugs and security problems, analysis and grasp the status of the network operation fastly and accurately in the vast and complex high-dimensional data information, then quickly recognise the network abnormal or invasion, accurately judge the development direction of network security threat, make sure the computer information network security technology actively develop into intelligent direction.

\section{The development direction of computer information network security technology}

Computer information network technology constantly improve, at the same time, the number of the social hacker attacked on computer networks becomes more and more, their skills also are higher. Many hackers theft information by againsting 
software, or release some fraud information in computer network etc., that affect the property and information security of the consumer. As soon as possible in order to clear the security problem of computer information network, the computer information network security technology in the continuous development and innovation, and emerged many new thoughts, ideas, methods, technologies and products. The development direction of computer information network security technology in our country can be summarized as the followings: one is the computer information network security technology will become a kind of security management platform in the direction of development from a single product. The security management platform is centered on security policy and effectively combines the single product, build and implement a series of safety management system. Second, by the development of the passive form into active development. Active development form can effectively respond to cyber attacks, traps and other security issues, and can automatically recover, also can effectively protect itself. Three, to develop in the direction of visualization of computer information network, studying in a variety of visual structure represent data information, so as to realize the visibility, local and global of the computer network information, to achieve the ultimate goal of computer information network visualization man-machine exchange. Four is intranet network information security technology become more perfectly, can effectively and accurately prevent software for users to implement attacks, the error of safety factor. Five, the computer information network security technology development direction from static to dynamic development direction. We will change the past passive attack and invasion of the computer information network system, active prevent and avoid attack and invasion, timely response to safety concerns, auto repair loopholes, invasion of hackers can anti-tracking positioning network IP and other direction.

\section{Conclusion}

The rapid development of computer network technology makes the importance of safety in the computer information network is increasing high. With the rapid development of information age, computer information network technology also has a lot of flying. The computer has provided many conveniences for people's life, at the same time, also brought a lot of difficult to solve the problem of security. To ensure that improve and solve the computer information network security must take certain information network security technology, and continuously provide conduct in-depth research, development and development. There are still needs about the future development of the computer information network security technology, constantly promote people's understanding of computer information network security, what can ensure that make the correct use of the computer information network technology.

\section{References}

1. C. Xu: Information system engineering, Vol. 3 (2014).

2. W.B. Wu, Z.R. Yang: Journal of Hebei University, Vol. 38 (2013).

3. B. Yang: Technology Wind, Vol. 20 (2012). 